\title{
Imobilização de lipase de Candida rugosa em suporte de quitosana por ligação covalente
}

Immobilization of Candida rugosa lipase on chitosan support through covalent bonding

\author{
V. S. Varandas ${ }^{1, *}$; R.D.M. Ferreira ${ }^{1}$;P. A. W. Cavalcante ${ }^{1}$; T. S. de Oliveira ${ }^{1}$; D. F. \\ Coêlho'; J. R. S. Rodrigues ${ }^{1}$; J. A. Freitas' ${ }^{2}$; R. R. de Souza ${ }^{1}$ \\ ${ }^{1}$ Departamento de Engenharia Química, Universidade Federal de Sergipe, 49000-1000, São Cristóvão-SE, Brasil \\ ${ }^{2}$ Departamento de Engenharia Ambiental, Universidade Federal de Sergipe, 49000-1000, São Cristóvão-SE, Brasil
}

*vinicius_varandas11@hotmail.com

(Recebido em 22 de julho de 2017; aceito em 07 de maio de 2018)

\begin{abstract}
A imobilização de enzimas abriu novos e promissores campos de atuação, entre eles, sua aplicação como catalisadores industriais de elevada eficiência. A alta especificidade e possibilidade de reuso têm permitido a gradual substituição de catalisadores convencionais. O presente trabalho teve como objetivo a produção de um biocatalisador através do estudo da imobilização de lipase em quitosana, ambos comerciais, por meio do método de ligação covalente. O suporte foi preparado por gotejamento de uma solução de quitosana em meio alcalino e posterior ativação com glutaraldeído, agente entrecruzante para a ligação covalente. Foram utilizadas concentrações de sinalizante entre 0 e $5 \%$ para avaliar qual a melhor em uma posterior imobilização. Verificou-se que as esferas ativadas a 3\% demonstraram melhores resultados na imobilização, as quais forneceram os menores valores de atividade residual e concentração de proteínas do sobrenadante, bem como um rendimento de $89,37 \%$. O biocatalisador produzido apresentou uma atividade catalítica máxima de 275,75 U/kg em substrato sintético, mantendo boa estabilidade mesmo após ser reutilizado nove vezes. Através dos testes de agitação, foi possível verificar que as esferas possuem resistência mecânica para suportar os ensaios de ativação e imobilização, além de possíveis aplicações em processos em batelada e em reatores de leito.
\end{abstract}

Palavras-chave: Imobilização, Lipase, Quitosana

The immobilization of enzymes has opened new and promising research fields, among them, its application as high efficiency industrial catalysts. The high specificity and possibility of reuse have allowed gradual replacement of conventional catalysts. The present work aimed the production of a biocatalyst, through the study of immobilization of lipase in chitosan, both commercial, using covalent bond method. The support was prepared by dripping a solution of chitosan in alkaline medium and subsequent activation with glutaraldehyde, as a crosslinking agent, for covalent bonding. Glutaraldehyde concentrations ranged between 0 and 5\% were used to evaluate the best for immobilization. Beads at 3\% showed better results in immobilization, which provided the lowest values of residual activity and protein concentration of the supernatant, as well as a yield of $89.37 \%$. The biocatalyst produced had a maximum catalytic activity of $275.75 \mathrm{U} / \mathrm{kg}$ in synthetic substrate, maintaining good stability even after being reused nine times. Agitation tests showed that such spheres have mechanical resistance to withstand the activation and immobilization tests, as well as possible applications in batch processes and in bed reactors.

Keywords: Immobilization, Lipase, Chitosan

\section{INTRODUÇÃO}

As enzimas são catalisadores biológicos macromoleculares de natureza predominantemente proteica, uma vez que reações catalisadas por RNA são também possíveis. Sua ação é semelhante à dos catalisadores inorgânicos, onde há uma redução da energia de ativação dos processos em que ocorram quaisquer alterações do equilíbrio termodinâmico e sem que as mesmas sejam consumidas nas reações químicas envolvidas. A principal diferença entre os catalisadores inorgânicos e as enzimas está na sua especificidade frente aos sítios ativos presentes no substrato (moléculas nas quais a enzima atuará). As enzimas podem ainda ser temporariamente modificadas por inibidores e ativadores, que são compostos que se ligam ao sítio ativo da enzima, ou do substrato, ocasionando 
a redução e intensificação da sua atividade, respectivamente [1]. Praticamente todos os processos metabólicos na célula requerem enzimas para que possam ocorrer a taxas suficientemente altas para sustentar a vida. O complexo enzima-substrato é o coração da reação enzimática, sendo utilizado como base para o desenvolvimento dos modelos cinéticos para estudo do seu comportamento cinético e descrição dos mecanismos das reações envolvidas [2].

Industrialmente, as enzimas produzidas são aplicadas na produção, conservação e modificação de produtos (animais ou vegetais e seus derivados), bem como na produção de medicamentos [3]. A imobilização enzimática consiste no confinamento físico da enzima sobre um suporte por meio de sua adsorção física, ou ligação covalente, retendo sua atividade catalítica e permitindo seu reuso [4]. Entre os diversos materiais utilizados como suporte estão a hidroxilapatita, alumina, sílica e carvão ativado [5].

As lipases são enzimas capazes de catalisar reações de hidrólise de triglicerídeos e que têm muitas aplicações, razão pela qual a sua participação no mercado mundial de enzimas industriais cresce significativamente. Estima-se que elas terão importância industrial comparável à das peptidases, que hoje em dia representam 25 a $40 \%$ das vendas de enzimas industriais [6]. Sua aplicabilidade é enorme, visto que além da reação de hidrólise podem catalisar reações de esterificação, interesterificação e transesterificação em meios não-aquosos ou restritos a água. Por esse motivo, as lipases são excelentes alternativas aplicáveis às indústrias de alimentos, oleoquímicas, farmacêuticas, de biossensores [7].

A lipase imobilizada pode ser utilizada na transesterificação enzimática de triglicerídeos em presença de etanol para a produção de biodiesel, uma vez que os problemas relacionados à formação de subprodutos indesejados são reduzidos e sua alta especificidade permite atingir conversões da ordem de $90 \%$ [8] e utilizar menos de $10 \%$ em peso do biocatalisador [9].

O objetivo deste trabalho foi avaliar o efeito da concentração do ativador no rendimento da imobilização da lipase em esferas feitas com quitosana. Além disso, ensaios de resistência mecânica e operacional avaliaram a reusabilidade das esferas obtidas e os parâmetros cinéticos para a enzima em questão foram obtidos.

\section{MATERIAL E MÉTODOS}

\subsection{CINÉTICA ENZIMÁTICA}

As constantes do modelo cinético de Michaelis-Menten foram determinadas através do ajuste do modelo não-linear utilizando a função de minimização nls da biblioteca STATS, contida no software R [10].Os dados experimentais foram obtidos através do método das velocidades iniciais, cujos valores foram estimados através da diferenciação finita dos dados obtidos, conforme descrito por Fogler (1999) [11].

\subsection{RENDIMENTO DE IMOBILIZAÇÃO}

Durante os ensaios realizados, além de acompanhar a atividade residual do sobrenadante, calculou-se o rendimento de imobilização, o qual é fundamental para avaliar o desempenho do processo. O rendimento de imobilização é definido como a quantidade teórica de enzima imobilizada, obtido segundo metodologia descrita por Brígida (2010) [12]:

$$
R(\%)=\left(1-\frac{A t_{s}}{A t_{d}}\right) * 100
$$

Onde $\mathrm{At}_{\mathrm{s}} \mathrm{e}$ a Atividade hidrolítica medida do sobrenadante após o processo de imobilização e $\mathrm{At}_{\mathrm{d}}$ é a Atividade hidrolítica medida da solução enzimática destinada à imobilização, antes do processo. 


\subsection{SÍNTESE E FUNCIONALIZAÇÃO DAS ESFERAS DE QUITOSANA}

Para a produção das esferas, $1 \mathrm{~g}$ de quitosana em pó foi solubilizada em $30 \mathrm{~mL}$ de solução acética $5 \%$. A solução obtida foi gotejada em um banho coagulante composto por uma solução de $\mathrm{NaOH}$ $1 \mathrm{M}$ contendo etanol a 26\% [13]. A solução foi gotejada utilizando uma bomba peristáltica e tubos com 2 milímetros de diâmetro interno. As esferas formadas permaneceram na solução coagulante por 12 horas, sendo lavadas e armazenadas em tampão fosfato $50 \mathrm{mM} \mathrm{pH} 7$ até sua funcionalização.

Para ativação do suporte, preparou-se soluções de glutaraldeído com concentrações entre 0 e 5\%, em tampão fosfato $50 \mathrm{mM} \mathrm{pH} 8$. Foram misturados $10 \mathrm{~mL}$ de solução ativadora, $5 \mathrm{~mL}$ de tampão TRIS-HCl $100 \mathrm{mM} \mathrm{pH} 9$ e $0,5 \mathrm{~g}$ de esferas de quitosana em um béquer, permanecendo sob agitação durante seis horas, a temperatura ambiente[13]. Em seguida, a solução foi filtrada e lavada sucessivamente com tampão para que todo excesso de glutaraldeído fosse removido.

\subsection{IMOBILIZAÇÃO ENZIMÁTICA}

Nesta etapa, 0,5g de esferas ativadas, juntamente com $10 \mathrm{~mL}$ de solução enzimática foram colocadas sob agitação por um período de $24 \mathrm{~h}$, a temperatura ambiente. Em seguida a solução foi filtrada e lavada com água destilada para remover o excesso de enzima não ligada ao suporte.

\subsection{DETERMINAÇÃO DE PROTEÍNAS TOTAIS E ATIVIDADES ENZIMÁTICAS}

A determinação da concentração de proteínas totais foi realizada segundo o método descrito por Bradford (1976) [14].

Para medida de atividade hidrolítica, foi analisada a reação de hidrólise do substrato p-NFL (pnitrofenillaurato). As soluções do substrato e da lipase foram feitas de acordo com a metodologia descrita por Amaral et al. (2006) [15]. A solução de substrato foi aquecida em banho maria a $37^{\circ} \mathrm{C}$ por 15 minutos e teve uma alíquota de $1,8 \mathrm{~mL}$ transferida para uma cubeta, sendo misturada a 0,2 $\mathrm{ml}$ de solução enzimática. A densidade ótica da mistura reacional foi medida a $410 \mathrm{~nm}$ após um intervalo de 100 segundos. Uma curva padrão espectrofotométrica foi obtida para o p-nitrofenol, de modo a obter a concentração do analito e calcular a atividade enzimática da mistura enzimática. Uma unidade de atividade enzimática é definida como a quantidade de enzima necessária para produzir um $\mu \mathrm{mol}$ de p-nitrofenol por minuto sob as condições de análise.

\subsection{ESTABILIDADE OPERACIONAL}

A reutilização da enzima imobilizada foi avaliada através da incubação de $0,5 \mathrm{~g}$ de esferas em 2 $\mathrm{mL}$ de substrato durante 10 minutos, com subsequente separação das esferas e análise da formação de p-nitrofenol na fase líquida, conforme descrito no método de determinação da atividade enzimática. Após cada ciclo, as esferas foram lavadas com água destilada para remoção de substrato e produto residuais. A lavagem foi repetida até que nenhuma coloração fosse carreada para a água de lavagem. Os ciclos foram realizados para esferas imobilizadas em diferentes concentrações de glutaraldeído (entre 0 e 5\%), como descrito no método de ativação das esferas. O número máximo de ciclos para uma dada condição foi aquele no qual a mistura reacional não fornecia medidas espectrofotométricas dentro da faixa de trabalho do equipamento.

\subsection{ESTABILIDADE MECÂNICA}

A resistência mecânica das esferas foi avaliada através da observação da perda de massa após serem mantidas sob agitação $(125,150,175 \mathrm{rpm})$ por 12 horas consecutivas. As esferas foram separadas de possíveis fragmentos utilizando peneira TYLER 20. 


\section{RESULTADOS E DISCUSSÃO}

\subsection{CINÉTICA ENZIMÁTICA}

Os resultados dos ensaios de velocidade inicial para a reação de hidrólise do paranitrofenillaurato, catalisado por lipase de Candida rugosa, estão apresentados na Figura 1. Observase que os dados apresentam um comportamento segundo o modelo de Michaelis-Menten da velocidade de reação frente ao substrato. Através da regressão não linear da equação, obteve-se os valores dos parâmetros para a lipase estudada de $\mathrm{Vm}=29,144 \mu \mathrm{mols} / \mathrm{mL} \cdot s \mathrm{e} \mathrm{Km}=243,5 \mu \mathrm{M}$.

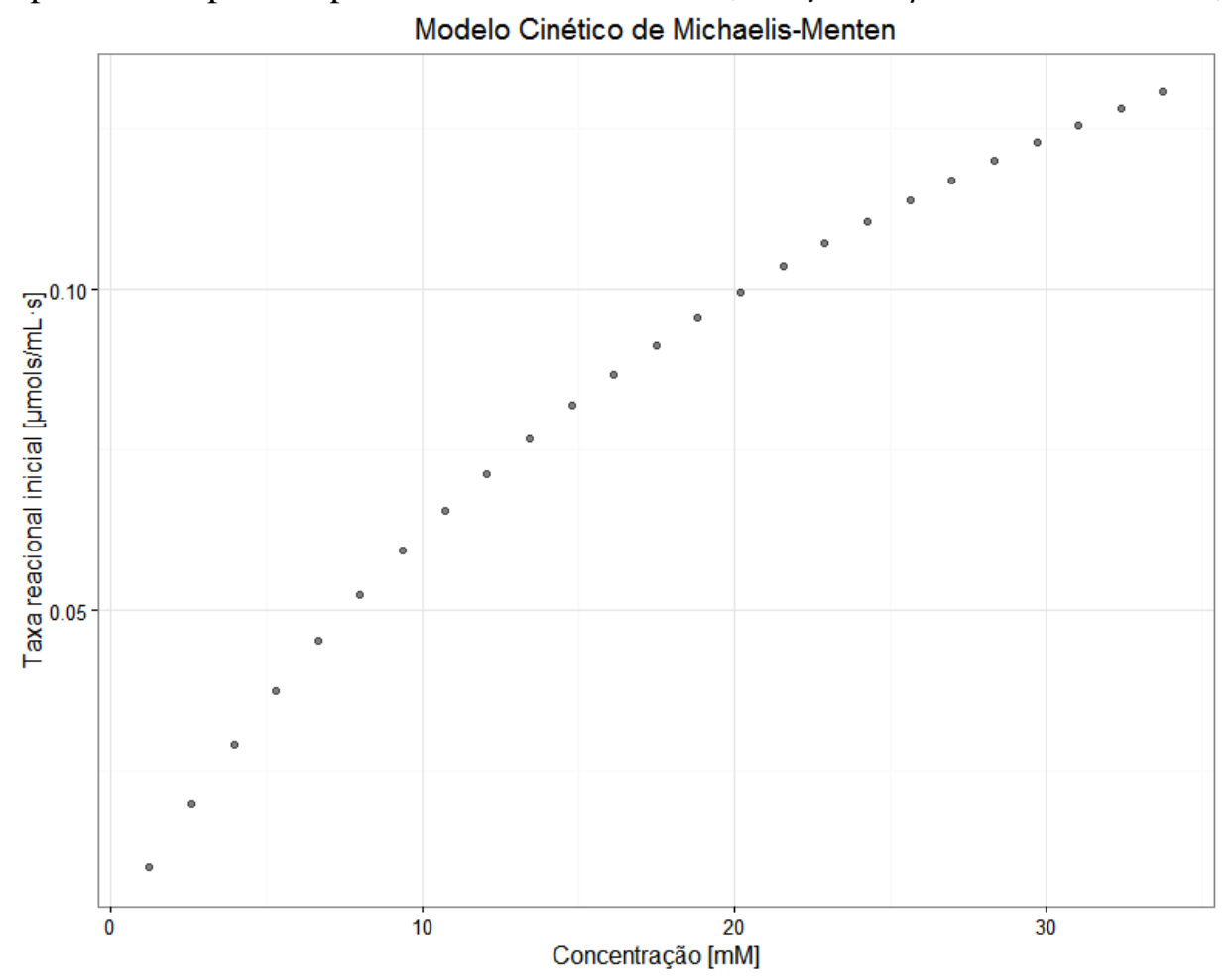

Figura 1: Influência da concentração do substrato na velocidade inicial de reação.

O valor estimado para a constante de Michaelis está na faixa registrada na literatura para esse substrato, comparando com o trabalho de Brígida [12] ( $\mathrm{Km}=192 \mu \mathrm{M})$ e Nawani e Kaur (2007) [16] ( lipase Ylip2, $\mathrm{Km}=190 \mu \mathrm{M}$ e lipase YIlp1, $\mathrm{Km}=500 \mu \mathrm{M}$ ). Quanto menor o valor de $\mathrm{Km}$, maior afinidade da enzima frente ao substrato.

\subsection{FUNCIONALIZAÇÃO DAS ESFERAS E IMOBILIZAÇÃO DA ENZIMA}

A funcionalização das esferas foi realizada conforme item 2.3 e teve como objetivo o uso do glutaraldeído como agente ativador de grupos químicos presente na quitosana. Esse procedimento fez-se necessário, pois a imobilização por ligação covalente requer a ativação do suporte (grupo amino) para poder gerar grupos reativos que se unirão à enzima através de grupos laterais do resíduo dos aminoácidos.

Cruz Júnior (2007) [13] destacou a importância da otimização da concentração de glutaraldeído ao ativar as esferas, visto que é uma variável fundamental na análise do rendimento de imobilização. Concentrações muito baixas podem não ativar grupos suficientes no suporte, enquanto que concentrações elevadas podem causar um impedimento estérico na molécula que se pretende imobilizar, nesse caso, a enzima.

A Figura 2 apresenta os valores de atividade enzimática e concentração de proteínas do sobrenadante, ambos obtidos após a imobilização no suporte ativado em diversas proporções de glutaraldeído. Pode-se perceber que, a partir de 3\%, o aumento na concentração de sinalizante foi acompanhando pelo aumento da concentração de proteína no sobrenadante e consequentemente da atividade residual do mesmo. 


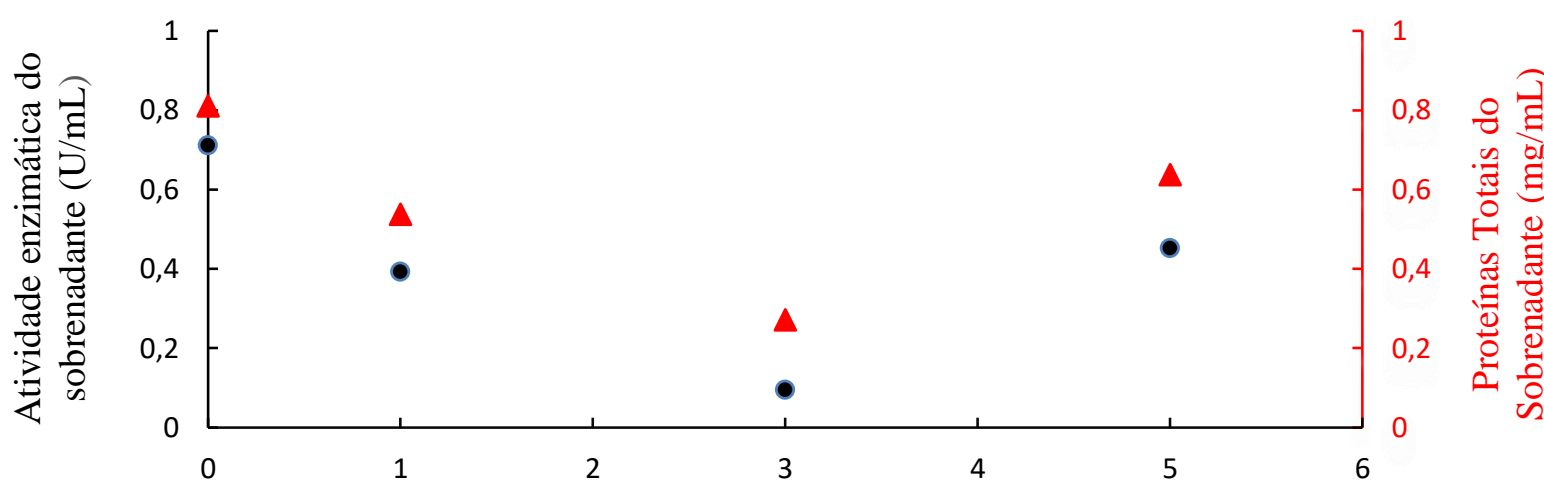

Concentração de Glutaraldeído (\%)

Figura 2: Concentração de proteína e atividade hidrolítica presentes no sobrenadante após imobilização em esferas ativadas a diferentes concentrações de glutaraldeído.

O experimento realizado em solução com $0 \%$ de glutaraldeído teve como objetivo avaliar se a enzima seria capaz de ser imobilizada nas esferas sem o entrecruzamento (ligação covalente), ou seja, migraria da solução por difusão até a superfície do suporte, em um processo típico de adsorção.

Com base nos dados acima, calculou-se o rendimento de imobilização para cada experimento através da Equação 1. Os valores estimados estão representados na Tabela 1.

Tabela 1: Rendimento de imobilização em função de esferas ativadas a diferentes concentrações de glutaraldeído

\begin{tabular}{ccccc}
\hline & \multicolumn{4}{c}{ Concentração de Glutaraldeído (\%) } \\
\cline { 2 - 5 } & 0 & 1 & 3 & 5 \\
\hline $\begin{array}{c}\text { Rendimento } \\
\text { de } \\
\text { Imobilização }\end{array}$ & $21,25 \%$ & $56,56 \%$ & $89,37 \%$ & $50 \%$ \\
\hline
\end{tabular}

Os resultados mostram que, na proporção de $3 \%$ de glutaraldeído, houve o melhor rendimento de imobilização, indicando que esta é a concentração que otimiza o processo de imobilização. $O$ baixo rendimento encontrado para $0 \%$ indica que uma ligação espontânea (sem o auxílio do sinalizante) entre a enzima e o suporte é pouco provável de ocorrer ou que a esfera não possui uma estrutura favorável à adsorção. O resultado pouco satisfatório para $1 \%$ indica uma ineficiência do processo de formação de grupos reativos para a quitosana.

Uma observação importante a ser destacada é o fato das esferas ativadas com solução 5\% terem apresentado maior rigidez quando comparadas às demais, tornando-se, consequentemente, menos resistentes e mais quebradiças. De acordo com Siso et al. (1997) [17], esse comportamento está relacionado com as espécies de ligações que são formadas entre as moléculas de quitosana quando as mesmas são submetidas à ativação com soluções de glutaraldeído mais concentradas[17].

Como todo catalisador heterogêneo, isto é, que está presente numa fase (sólida) diferente da mistura reacional, o biocatalisador (enzima e suporte) estudado deve atender a alguns critérios de excelência para ser aplicado em escala industrial, entre eles: elevada atividade, alta seletividade, estabilidade, para que tenha sua propriedade catalítica mantida por muitos ciclos e resistência mecânica.

Seguindo esses critérios, realizou-se o estudo de estabilidade operacional para observar em quantos ciclos o biocatalisador mantinha sua atividade catalítica. A Figura 3 apresenta a estabilidade para esferas ativadas a diferentes concentrações de sinalizante, conforme item 2.6. 


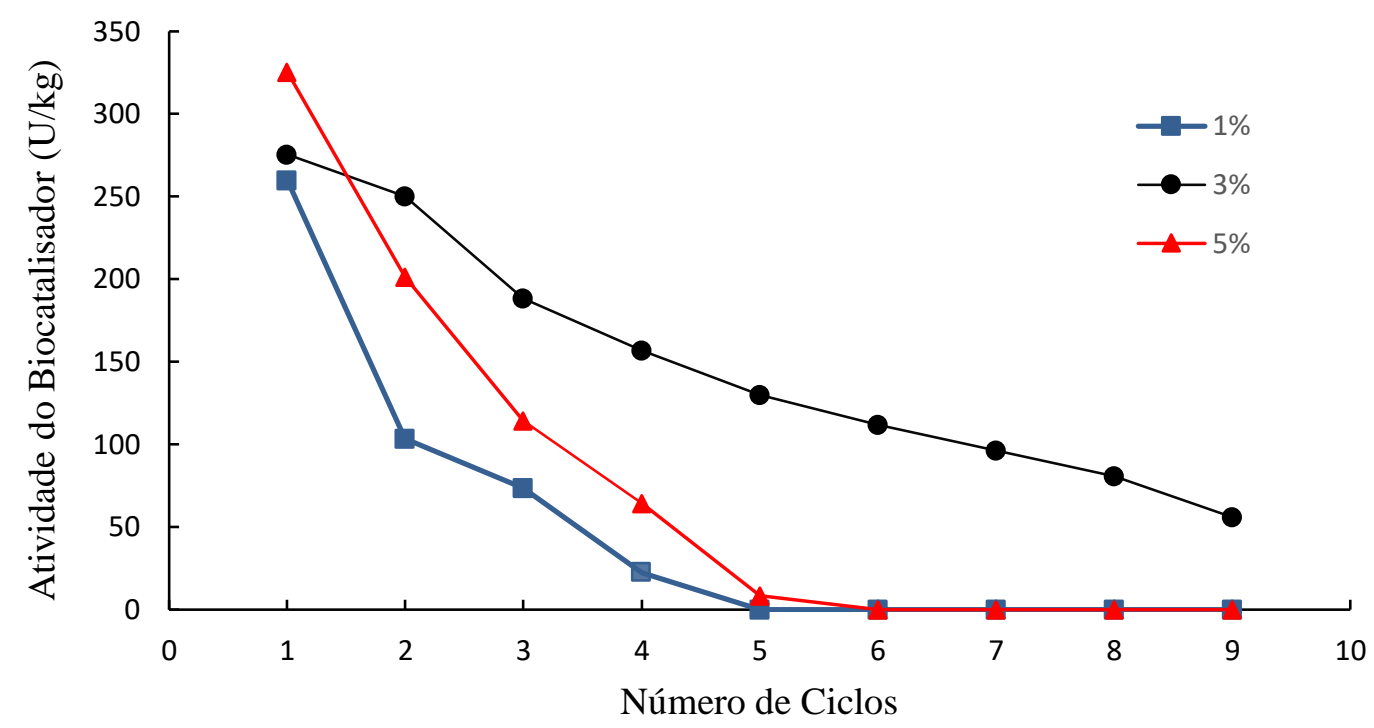

Figure 3: Atividade dos biocatalisadores ativados em diferentes concentrações de glutaraldeído em cada ciclo.

Percebe-se que as esferas ativadas em solução a 3\% de ativador apresentaram-se mais estáveis, mantendo sua propriedade catalítica mesmo após nove ciclos. Já 1 e 5\% apresentaram quedas significativas nos valores de atividade ciclo após ciclos, o que evidencia a ineficiência no processo de ativação bem como a possibilidade de a enzima ter ficado apenas retida na superfície do suporte, ou seja, não ligada. Como o próprio meio aquoso do substrato favorece a dessorção, grande parte dessa enzima adsorvida foi perdida durante as lavagens realizadas entre os ciclos, reduzindo com isso efeito catalítico do biocatalisador.

Os biocatalisadores heterogêneos apresentam uma vasta gama de aplicações, entre elas a transesterificação de óleos para a produção de biodiesel, seja em reator de leito ou batelada. Para suportar os intensos processos de agitação exigidos pelo reator batelada, realizou-se ensaios de resistência mecânica, ou seja, resistência à quebra, do biocatalisador em estudo.

Tabela 2: Perda percentual de massa das esferas de quitosana em função de diferentes níveis de agitação

\begin{tabular}{ccc}
\hline Massa de Esferas (g) & $\begin{array}{c}\text { Resistência Mecânica } \\
\text { Agitação (rpm) }\end{array}$ & Perda de Massa (\%) \\
\hline $\mathbf{0 , 4 5 6 8}$ & 125 & 0,57 \\
\hline $\mathbf{0 , 4 6 7 3}$ & 150 & 0,68 \\
\hline $\mathbf{0 , 4 5 4 7}$ & 175 & 0,84 \\
\hline $\mathbf{0 , 4 7 1 2}$ & 200 & 1,27 \\
\hline $\mathbf{1 , 7 2 3 0}$ & 200 & 5,53 \\
\hline
\end{tabular}

Os resultados apresentados demonstram que a perda de massa não foi significativa, na ordem de $1 \%$, o que evidencia a resistência do biocatalisador. É importante destacar que a maior perda ocorreu em função de uma massa maior do mesmo e não em virtude da agitação, ou seja, o choque entre as esferas provocava a própria destruição.

\section{CONCLUSÃO}

Os ensaios de imobilização de lipase em quitosana demonstraram que as mesmas possuem resistência mecânica para suportar o longo período de agitação exigido pela funcionalização e imobilização, bem como serem aplicadas em outros processos envolvendo reatores bateladas ou sistemas dinâmicos (reator de leito). Verificou-se ainda que a concentração de sinalizante, durante a funcionalização, que otimizou todo o processo foi de 3\%. Isto indica que, em concentrações menores do agente ativador, a eficiência da ligação covalente é maior, a qual foi avaliada por 
medida de atividade residual e concentração de proteínas no sobrenadante, bem como da estabilidade do biocatalisador, que manteve sua atividade por mais ciclos quando comparados aos demais.

\section{AGRADECIMENTOS}

Os autores gostariam de agradecer a CAPES e CNPq pelo suporte financeiro e concessão de bolsas.

\section{REFERÊNCIAS BIBLIOGRÁFICAS}

1. Berg JM, Tymoczko JL, Stryer L. Biochemistry. New York, NY [etc.]: Freeman; 2006.

2. Borracini HMP. Estudo do processo de extração da bromelina por micelas reversas em sistema de descontinuo [Dissertação de Mestrado]. Campinas, SP: Universidade Estadual de Campinas - UNICAMP; 2006.

3. Coêlho DdF. Purificação de bromelina dos resíduos de abacaxi (Ananas comosus L.Merril) por precipitação integrada a sistema bifásico aquoso (PEG/Sulfato de amônio) não convencional [Dissertação de Mestrado]. Campinas: Universidade Estadual de Campinas; 2012.

4. Katchalski-Katzir E, Kraemer DM. Eupergit ${ }^{\circledR}$ C, a carrier for immobilization of enzymes of industrial potential. J Mol Catal B: Enzym. 2000;10(1):157-76, doi:10.1016/S1381-1177(00)00124-7.

5. Reguly JC. Biotecnologia dos Processos Fermentativos. Pelotas: Editora Gráfica Universitária - EDUFPel; 1996.

6. Sharma R, Chisti Y, Banerjee UC. Production, purification, characterization, and applications of lipases. Biotechnol Adv. 2001;19(8):627-62, doi:10.1016/S0734-9750(01)00086-6.

7. Silva NC, Miranda JS, Bolina IC, Silva WC, Hirata DB, de Castro HF, et al. Immobilization of porcine pancreatic lipase on poly-hydroxybutyrate particles for the production of ethyl esters from macaw palm oils and pineapple flavor. Biochem Eng J. 2014;82:139-49, doi:10.1016/j.bej.2013.11.015.

8. Arumugam A, Ponnusami V. Biodiesel production from Calophyllum inophyllum oil using lipase producing Rhizopus oryzae cells immobilized within reticulated foams. Renewable Energy. 2014;64:27682, doi:10.1016/j.renene.2013.11.016.

9. Cervero J, Alvarez J, Luque S. Novozym 435-catalyzed synthesis of fatty acid ethyl esters from soybean oil for biodiesel production. Biomass Bioenergy. 2014;61:131-7, doi:10.1016/j.biombioe.2013.12.005.

10. R Core Team. R: A Language and Environment for Statistical Computing. Vienna, Austria: R Foundation for Statistical Computing; 2015.

11. Fogler HS. Elements of chemical reaction engineering 1999.

12. Brígida AIS. Imobilização de lipases utilizando fibra da casca de coco verde como suporte para aplicações industriais [Doutorado]. Rio de Janeiro - RJ: Tese. Escola de Química. Universidade Federal do Rio de Janeiro. Rio de Janeiro. 197p; 2010.

13. Cruz Júnior A. Imobilização de lipase de Candida antarctica B em quitosana para obtenção de biodiesel por transesterificação do óleo de mamona [Mestrado]. Florianópolis, SC: Universidade Federal de Santa Catarina; 2007.

14. Bradford MM. A rapid and sensitive method for the quantitation of microgram quantities of protein utilizing the principle of protein-dye binding. Anal Biochem. 1976;72(1-2):248-54, doi:10.1016/00032697(76)90527-3.

15. Amaral PF, Rocha-Leão MHM, Marrucho IM, Coutinho JA, Coelho MAZ. Improving lipase production using a perfluorocarbon as oxygen carrier. J Chem Technol Biotechnol. 2006;81(8):1368-74, doi:10.1002/jctb.1478.

16. Nawani N, Kaur J. Studies on lipolytic isoenzymes from a thermophilic Bacillus sp.: Production, purification and biochemical characterization. Enzyme Microb Technol. 2007;40(4):881-7, doi:10.1016/j.enzmictec.2006.07.006.

17. Siso MG, Lang E, Carrenõ-Gómez B, Becerra M, Espinar FO, Méndez JB. Enzyme encapsulation on chitosan microbeads. Process Biochem. 1997;32(3):211-6, doi:10.1016/S0032-9592(96)00064-7. 